\title{
PENGARUH PEMAHAMAN ETIKA BISNIS ISLAM TERHADAP MOTIVASI KERJA KARYAWAN DAN KUALITAS PELAYANAN KARYAWAN BANK MUAMALAT CABANG JAMBI
}

Muhammad Andriyansyah ${ }^{1}$, Yudha Gusti Wibowo ${ }^{2}$

Program Ekonomi Syariah, STAI Batanghari, Jambi

Program Pascasarjana, Universitas Jambi

Email korespondensi:aan.stai@yahoo.com

\section{ABSTRACT}

Quality of service is very important in the business of financial services, including in it is a service business finance that is managed by sharia. One of the syariah financial institutions that do business financial services is Bank Muamalat Branch Jambi. Service quality is determined by many factors, two of which are an understanding of Islamic Business Ethics and Employee Work Motivation. This study examines the problems related to the influence of Understanding Islamic Business Ethics on Employee Motivation and Quality of Employee Services at Muamalat Bank Jambi Branch. The approach used is a quantitative approach by examining three variables, namely understanding Islamic business ethics, employee work motivation, and employee service quality.

Keywords: Understanding Islamic Business Ethics, Employee Work Motivation, Employee Service Quality.

Latar Belakang 
Bank syariah (Islamic banking atau interest-free banking) adalah lembaga keuangan berdasarkan etika dan sistem nilai Islam yang bebas dari bunga (riba), kegiatan spekulatif yang non-produktif seperti perjudian, bebas dari hal-hal yang tidak jelas dan meragukan (tidak pasti), berprinsip pada keadilan dan hanya membiayai kegiatan usaha yang halal, investasi yang beretika, mengedepankan nilai-nilai kebersamaan dan persaudaraan dalam berproduksi. ${ }^{1}$

Untuk menjalankan bisnis didalam perbankan syariah khususnya bank muamalat cabang jambi yang menggunakan sistim bagi hasil, dinilai dibutuh pemahaman yang baik bagi semua komponen yang terkait dan terlibat didalam perbankan syariah tersebut tentang Etika Bisnis di dalam Islam, agar dapat meningkatkan motivasi dan kualitas pelayanan karyawan yang baik pula. $^{2}$ Dalam bertransaksi agar tidak ada salah satu pihak yang terzalimi atau dirugikan sebagaimana disebutkan dalam Al-quran,

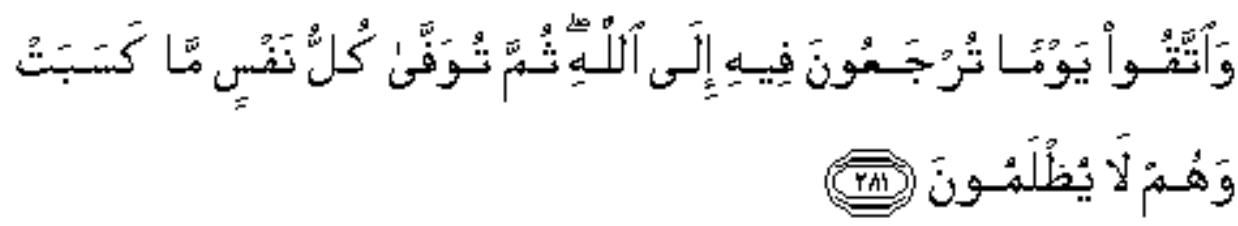

"Dan takutlah pada hari (ketika) kamu dikembalikan kepada Allah, kemudian setiap orang diberi balasan yang sempurna sesuai dengan apa yang telah dilakukannya, dan mereka tidak dizalimi (dirugikan) (Al-Baqarah 281). "

Etika Bisnis Islam secara tidak langsung mempelajari tentang mana yang mengandung hal baik atau hal yan buruk, benar atau salah sesuai dengan prinsip-prinsip moralitas. Jadi etika bisnis merupakan sebuah pemikiran atau refleksi tentang moralitas dalam ekonomi dan bisnis. dalam etika bisnis islam yang di atur dalam Al-Quran bukan semata-semata upaya meraih keuntungan material, tetapi sekaligus berupaya mencapai tujuan

\footnotetext{
Abdul Wahab, "Faktor-faktor yang Mempengaruhi Perilaku Masyarakat Muslim dalam Memilih Perbankan Syariah di Kota Makasar”, Tesis Magister, UIN Alauddin Makasar, hal. 131.

2 Muhamad Ayub, Op Cit. , hal. 101.
} 
spiritual, yakni pencapaian tujuan kemanusian sebagai makhluk dan khalifah untuk mencapai keridhoan Allah SWT. ${ }^{3}$

Pada umumnya orang mau bekerja karena didorong oleh keinginan untuk dapat memenuhi kebutuhan fisik dan rohani. Sedangkan perusahaan selalu mengharapkan agar karyawannya dapat bekerja dengan giat, mematuhi peraturan atau disiplin serta menghasilkan prestasi kerja yang baik, karena hanya dengan cara ini suatu perusahaan dapat mencapai tujuannya dengan tingkat produktifitas yang tinggi. Untuk menyatukan keinginan karyawan dan kepentingan perusahaan tersebut dan terciptanya kerjasama yang saling memberikan kepuasan bagi kedua belah pihak dibutuhkan suatu cara adalah dengan meningkatkan motivasi kerja karyawan.

Motivasi adalah proses yang menjelaskan intensitas, arah, dan ketekunan seorang individu untuk mencapai tujuannya. Sedangkan menurut hasibuan motivasi adalah rangsangan keinginan dan pemberian daya penggerak yang menciptakan kegairahan kerja seseorang agar mereka mau bekerja sama, bekerja efektif, dan terintegrasi dengan segala upayanya untuk mencapai kepuasan. ${ }^{4}$ Dari definisi diatas dapat diambil kesimpulan bahwa motivasi kerja adalah suatu dorongan atau proses mempengaruhi karyawan untuk bekerja demi memuaskan kebutuhan hidupnya.

Islam juga mendorong kebebasan melakukan bisnis dan transaksi financial berdasarkan beberapa larangan, etika, dan moral. Selain beberapa larangan utama, hukum Islam menetapkan serangkaian norma dan batasan lain dalam rangka menghindari keuntungan yang tidak sewajarnya dan ketidakadilan. ${ }^{5}$ Tujuan dari pelayanan yang baik adalah mencegah pembelotan dan membangun kesetiaan pelanggan atau customer loyality. Pembelotan pelanggan atau berpalingnya pelanggan disebabkan karena

3 http://duniailmuweb. blogspot. com/2012/05/bab-i-pendahuluan_29.html

4 Edy Sutrisno, Manajemen Sumber Daya Manusia (Jakarta:Kencana Prenada Media Group, 2009), hal. 111.

5 Muhammad Ayub, Understanding Islamic finance (Jakarta, PT Gramedia Pustaka Utama, 2009), hal. 67. 
kesalahan pemberian pelayanan maupun sistim yang digunakan oleh perusahaan dalam melayani pelanggan. ${ }^{6}$

Berdasarkan uraian diatas dapat ditarik suatu kesimpulan bahwa kualitas pelayanan adalah suatu hal yang memiliki nilai tinggi dan memuaskan kesenangan para pengguna jasa dengan berupaya untuk terus menerus menambah kesempurnaan atau memperbaiki kelemahan-kelemahan.

Berdasarkan latar belakang masalah seperti yang telah diuraikan diatas, maka dapat disimpulkan bahwa yang menjadi pokok masalah dalam penelitian ini adalah sebagai berikut :

1. Apakah pemahaman Karyawan tentang Etika Bisnis Islam berpengaruh terhadap motivasi kerja karyawan pada Bank Muamalat Cabang Jambi?

2. Apakah pemahaman Karyawan tentang Etika Bisnis Islam berpengaruh terhadap Kualitas Pelayanan Karyawan pada Bank Muamalat Cabang Jambi?

karena dengan penerapan etika bisnis islam dirasakan memiliki pengaruh terhadap motivasi kerja karyawan dan kualitas pelayanan karyawan, maka hal inilah yang diangkat menjadi latar belakang dan alasan pemilihan judul peneliti yaitu:"Pengaruh Pemahaman Etika Bisnis Islam Terhadap Motivasi Kerja Karyawan pada Bank Muamalat Cabang Jambi.

\section{Kerangka Pikir}

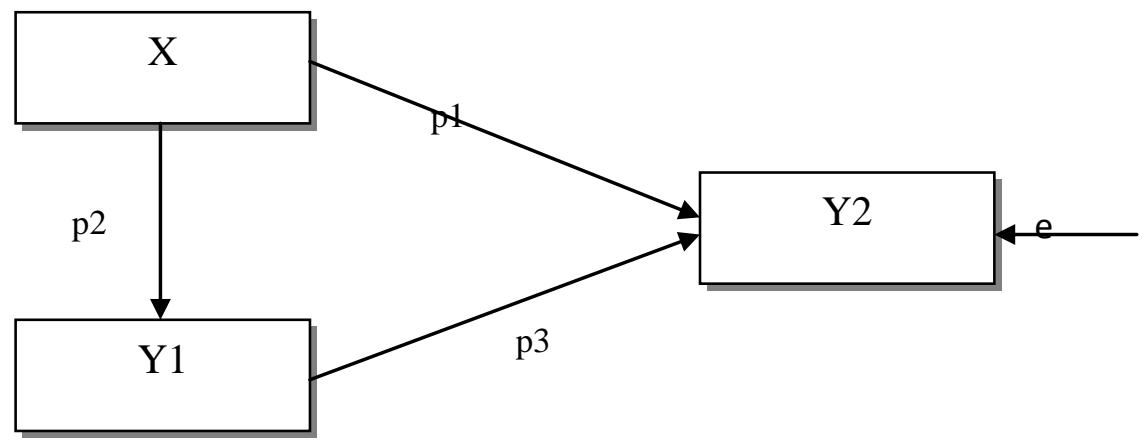

Ahmad Diqin, "Pengaruh Pelayanan Costomer Servic Terhadap Kepuasan Nasabah diBank Muamalat”,Proposal Penelitian, 2014, hal, 2 


\section{METODOLOGI PENELITIAN}

\section{A. Pendekatan Penelitian}

Penelitian ini dilakukan di Bank Muamalat Cabang Jambi, yang tepatnya beralamat di daerah murni kota jambi. Penelitian ini adalah penelitian kuantitatif menggunakan pendekatan Statistik Inferensi yaitu statistic yang dimaksudkan untuk menguji hipotesis, baik hipotesis nol $\left(\mathrm{H}_{0}\right)$ maupun hipotesis alternative $\left(\mathrm{H}_{\mathrm{a}}\right)$ mengenai kekuatan, keeratan, dan signifikansi hubungan antar variabel, Model yang digunakan dalam analisis penelitian menggunakan model Path Analysis, Model Path Analysis yang dibicarakan adalah pola hubungan sebab akibat. ${ }^{7}$

Dalam penelitian ini penulis menggunakan beberapa metode yaitu: metode Wawancara, merupakan metode pengumpulan data dengan cara bertanya langsung dengan responden. ${ }^{8}$ dan metode Kuesioner/Angket, merupakan teknik pengumpulan data yang dilakukan dengan cara memberi seperangkat pertanyaan atau pernyataan tertulis kepada responden untuk dijawabnya. ${ }^{9}$

Populasi dan sampel dalam penelitian ini adalah seluruh karyawan pada Bank Muamalat Cabang Jambi. Populasi dalam penelitian ini berjumlah 101 orang karyawan. Jumlah sampel ditentukan dengan menggunakan rumus slovin berikut ini:

$$
\mathrm{n}=\frac{N}{1+N e^{2}}
$$

$$
\begin{aligned}
& \mathrm{n}=\text { Jumlah sampel representatif yang diperlukan } \\
& \mathrm{N}=\text { Jumlah populasi keseluruhan } \\
& \mathrm{e}=\text { Tingkat signifikansi (error) yang ditetapkan peneliti. }
\end{aligned}
$$

\footnotetext{
${ }^{7}$ Sayid Syekh, Pengantar Statistik Ekonomi dan Sosial (Jakarta: Gaung Persada Perss, 2011), hal. 100

8 Amri Amir,Junaidi, dan Yulmardi,Op Cit. , hal. 166.

9 Sugiyono, Metode Penelitian Kuantitatif Kualitatif dan R\&D, (Bandung: ALFABETA, 2010), hal. 142.
} 
162 | Muhammad Andriyansyah dan Yudha Gusti Wibowo : Pengaruh Pemahaman Etika Bisnis.....

Berdasarkan rumus tersebut, maka jumlah sampel dalam penelitian ini dapat dihitung sebagai berikut:

$$
\begin{aligned}
\mathrm{n} & =\frac{N}{1+N e^{2}}=\frac{101}{1+101(0.01)^{2}} \\
& =\frac{101}{1+101(0,001)}=\frac{101}{1+0,0101}=\frac{101}{1,0101} \\
& =99,9 \text { dibulatkan menjadi } 100 \text { orang }
\end{aligned}
$$

Berdasarkan perhitungan di atas, maka jumlah sampel dalam penelitian ini adalah sebanyak 100 orang Karyawan Bank Muamalat Cabang Jambi.

Analisis Path Untuk mengetahui besarnya pengaruh Etika bisnis Islam terhadap Motivasi kerja karyawan dan Kualitas pelayanan Bank Muamalat Cabang Jambi, digunakan model persamaan Path analysis sebagai berikut; ${ }^{10}$

Diagram Jalur

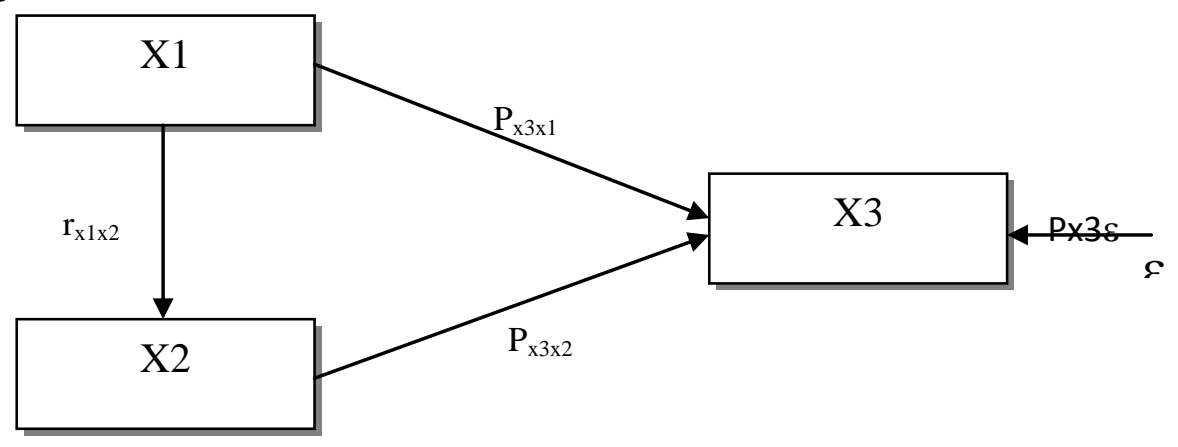

Keterangan:

$\mathrm{X} 1=$ Etika Bisnis Islam

$\mathrm{X} 2$ = Motivasi Kerja Karyawan

$\mathrm{X} 3$ = Kualitas Pelayanan

10 Sambas Ali Muhidin dan Maman Abdurahman, Analisis Korelasi, Regresi, dan Jalur Dalam Penelitian (Bandung: CV. Pustaka Setia, 2007), hal. 228. 
$\mathrm{r}_{\mathrm{x} 1 \times 2}=$ Koefisien korelasi variabel etika bisnis Islam X1 dengan motivasi kerja karyawan X2, menggambarkan intensitas keeratan hubungan antara variabel etika bisnis Islam dengan motivasi kerja karyawan.

$\mathrm{P}_{\mathrm{x} 3 \mathrm{x} 1}=$ Koefisien jalur variabel etika bisnis Islam X1 dengan kualitas pelayanan X3, menggambarkan besarnya pengaruh langsung antara variabel etika bisnis Islam terhadap kualitas pelayanan.

$\mathrm{P}_{\mathrm{x} 3 \mathrm{x} 2}=$ Koefisien jalur variabel motivasi kerja karyawan X2 dengan kualitas pelayanan X3, menggambarkan besarnya pengaruh langsung antara variabel motivasi kerja karyawan terhadap kualitas pelayanan.

$\mathrm{P}_{\mathrm{x} 3} \varepsilon=$ Koefisien jalur variabel residu $\varepsilon$ terhadap kualitas pelayanan X3, menggambarkan besarnya pengaruh langsung antara variabel residu $\varepsilon$ terhadap kualitas pelayanan.

Persamaan struktural untuk diagram jalur diatas adalah:

$$
\mathrm{X} 3=\mathrm{P}_{\mathrm{x} 3 \mathrm{x} 1} \mathrm{X}_{1}+\mathrm{P}_{\mathrm{x} 3 \mathrm{x} 1} \mathrm{X}_{2}+\varepsilon
$$

\section{HASIL PENELITIAN}

\section{A. Hasil Penelitian dan Analisis Hasil Penelitian}

\section{Pengujian Model (Path Analysis) dan Uji Hipotesis}

Pengujian data dilakukan dengan analisis jalur (path analysis), yaitu menguji pola hubungan yang mengungkap pengaruh variabel dengan atau seperangkat veriabel terhadap variabel lainnya,

\section{a. Langkah Pertama}

Langkah pertama dalam analisis jalur adalah merancang model berdasarkan konsep dan teori, secara teoritis.

a) Variabel pemahaman etika bisnis Islam (X) berpengaruh signifikan secara langsung terhadap motivasi kerja karyawan (Y1) PT. Bank Muamalat, Tbk. Cabang Jambi. 
164 | Muhammad Andriyansyah dan Yudha Gusti Wibowo : Pengaruh Pemahaman Etika Bisnis.....

b) Variabel pemahaman etika bisnis Islam (X) berpengaruh signifikan secara langsung terhadap kualitas pelayanan $\left(\mathrm{Y}_{2}\right)$ PT. Bank Muamalat, Tbk. Cabang Jambi.

c) Variabel motivasi kerja karyawan $\left(\mathrm{Y}_{1}\right)$ berpengaruh signifikan secara langsung terhadap kualitas pelayanan karyawan $\left(\mathrm{Y}_{2}\right)$ PT. Bank Muamalat, Tbk. Cabang Jambi.

2. Langkah Kedua

Melakukan pemeriksaan terhadap asumsi yang melandasi analisis jalur, yaitu hubungan antar variabel adalah linier dan aditif. Model yang digunakan rekrusif yaitu sistem aliran kausal satu arah, sedangkan model resiprokal atau aliran kausal yang dua arah (bolak-Balik) tidak dapat dianalisis. Penilaian terhadap asumsi tersebut dapat digambarkan seperti terlihat pada diagram path dalam gambar 4.2.

Berdasarkan gambar maka hubungan antar variabel adalah linier, yaitu sistem aliran ke satu arah, tidak ada variabel endogen yang mempunyai pengaruh bolak balik.

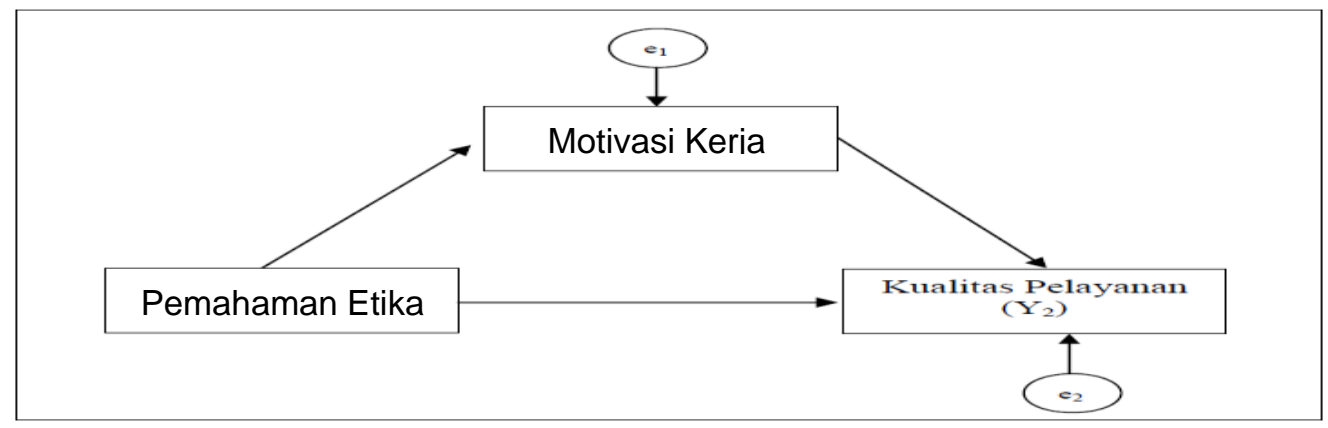

Gambar 1. Penggambaran Asumsi Analisis Jalur

3. Langkah Ketiga

Langkah ketiga didalam analisis jalur adalah pendugaan parameter atau perhitungan koefisien path. Untuk pendugaan parameter dilakukan dengan analisis regresi melalui software SPSS 22.0 for windows. Hasil dari analisis substruktur persamaan disajikan pada bagian berikut berikut ini. 
Muhammad Andriyansyah dan Yudha Gusti Wibowo : Pengaruh Pemahaman Etika Bisnis.... | 165

Summary dan Koefisien Jalur 1

Substruktur 1

$\mathrm{Y}_{1}$

$$
=\alpha+\beta_{1} \mathrm{X}+\mathrm{e}_{1}
$$

$\mathrm{Y}_{1}$

$$
=86,32+2,349 X
$$

Beta

$$
=0,322
$$

$\mathrm{R}^{2}$

$$
=0,715
$$

Error Term $(\mathrm{e} 1) \quad=\sqrt{1-R^{2}}$

$$
\begin{aligned}
& =\sqrt{1-0,715^{2}} \\
& =0,699
\end{aligned}
$$

Summary dan Koefisien Jalur 2

Substruktur 2

$$
\begin{array}{lll}
\mathrm{Y}_{2} & =\alpha+\beta_{2} \mathrm{X}+\beta_{3} \mathrm{Y}_{1}+\mathrm{e}_{2} \\
\mathrm{Y}_{2} & =34,546+0,842 \mathrm{X}+1,914 \mathrm{Y}_{1} \\
\text { Beta } & =0,714 \quad 1,202 \\
\mathrm{R}^{2} & =0,844 \\
\text { Error Term }\left(\mathrm{e}_{2}\right) & =\sqrt{1-R^{2}} \\
& & =\sqrt{1-0,844^{2}} \\
& =0,311 \\
& =0,537
\end{array}
$$


Berdasarkan Summary dan Koefisein jalur 1 dan 2 maka dapat diketahui besarnya pengaruh langsung, pengaruh tidak langsung dan pengaruh total antar variabel. Perhitungan pengaruh antar variabel adalah sebagai berikut.

a. Pengaruh Langsung

1) Pengaruh langsung variabel pemahaman etika bisnis Islam terhadap variabel motivasi kerja dapat dilihat dari nilai beta atau standardized coefficient adalah

$\mathrm{X} \rightarrow \mathrm{Y}_{1} \quad=\mathrm{p}_{1}=0,322$

2) Pengaruh langsung variabel pemahaman etika bisnis Islam terhadap variabel kualitas pelayanan dapat dilihat dari nilai beta atau standardized coefficient adalah

$\mathrm{X} \rightarrow \mathrm{Y}_{2} \quad=\mathrm{p}_{2}=0,471$

3) Pengaruh langsung variabel motivasi kerja karyawan terhadap variabel kualitas pelayanan dapat dilihat dari nilai beta atau standardized coefficient adalah

$\mathrm{Y}_{1} \rightarrow \mathrm{Y}_{2} \quad=\mathrm{p}_{3}=0,459$

b. Pengaruh Tidak Langsung

Pengaruh variabel pemahaman etika bisnis Islam terhadap variabel kualitas pelayanan melalui variabel motivasi kerja karyawan PT. Bank Muamalat, Tbk. Cabang Jambi dapat diperoleh dengan menggunakan rumus sebagai berikut.

$$
\begin{aligned}
X \rightarrow Y_{1} \rightarrow Y_{2} & =\left(p_{1} \times p_{3}\right) \\
& =(0,322 \times 0,459) \\
& =0,148
\end{aligned}
$$

Nilai sebesar 0,148 memiliki arti bahwa pengaruh tidak langsung pemahaman bisnis Islam terhadap kualitas pelayanan melalui variabel 
motivasi kerja karyawan PT. Bank Muamalat, Tbk. Cabang Jambi adalah sebesar 0,148 atau 14,8 persen.

c. Pengaruh Total

Pengaruh total diperoleh dari hasil perhitungan dengan menggunakan rumus berikut.

$$
\begin{aligned}
\text { Total Effect } & =\text { pengaruh langsung }+ \text { pengaruh tidak langsung } \\
& =\mathrm{p}_{2}+\left(\mathrm{p}_{1} \times \mathrm{p}_{3}\right) \\
& =0,471+(0,322 \times 0,459) \\
& =0,471+0,148 \\
& =0,619
\end{aligned}
$$

Pengaruh total pemahaman etika bisnis Islam terhadap motivasi kerja dan kualitas pelayanan karyawan PT. Bank Muamalat, Tbk. Cabang Jambi adalah sebesar 0,619 atau 61,9 persen.

4. Langkah keempat

Langkah keempat dalam analisis jalur adalah melakukan pemeriksaan terhadap validitas model. Terdapat dua indikator untuk melakukan pemeriksaan validitas model yaitu koefisien determinasi total dan theory trimming yang hasilnya dapat disajikan sebagai berikut.

a. Hasil Koefisien Detereminasi total

$$
\begin{aligned}
\mathrm{R}_{\mathrm{m}}^{2} & =1-\left(\mathrm{e}_{1}\right)^{2}\left(\mathrm{e}_{2}\right)^{2} \\
& =1-(0,699)^{2}(0,573)^{2}=0,839
\end{aligned}
$$

Berdasarkan hasil perhitungan rumus koefisien determinasi total maka diperoleh bahwa keragaman data yang didapat dijelaskan oleh model adalah sebessar 83,9 persen atau dengan kata lain informasi yang terkandung dalam data sebesar 83,9 persen dapat dijelaskan oleh model, sedangkan sisanya yaitu 16,1 persen dijelaskan oleh variabel lain (tidak terdapat dalam model) dan error.

b. Theory Trimimng

Pendekatan ini dilakukan dengan membuang jalur-jalur yang non signifikan agar memperoleh model yang benar-benar didukung oleh data empiris. Sebuah model menghasilkan bentuk hubungan yang valid 
dengan nilai level of significant (sig) $<0,05$. Level of significant (sig) masing-masing variabel adalah.

Substruktur $1 \mathrm{X}=0,000<0,05$; Subtruktur $2 \mathrm{X}=0,000<0,05 ; \mathrm{Y}_{1}$

$$
=0,000<0,05
$$

Berdasarkan hasil tersebut dapat dinyatakan bahwa seluruh jalur yang dibangun dalam model konstruk sebelumnya dinyatakan valid dan sahih.

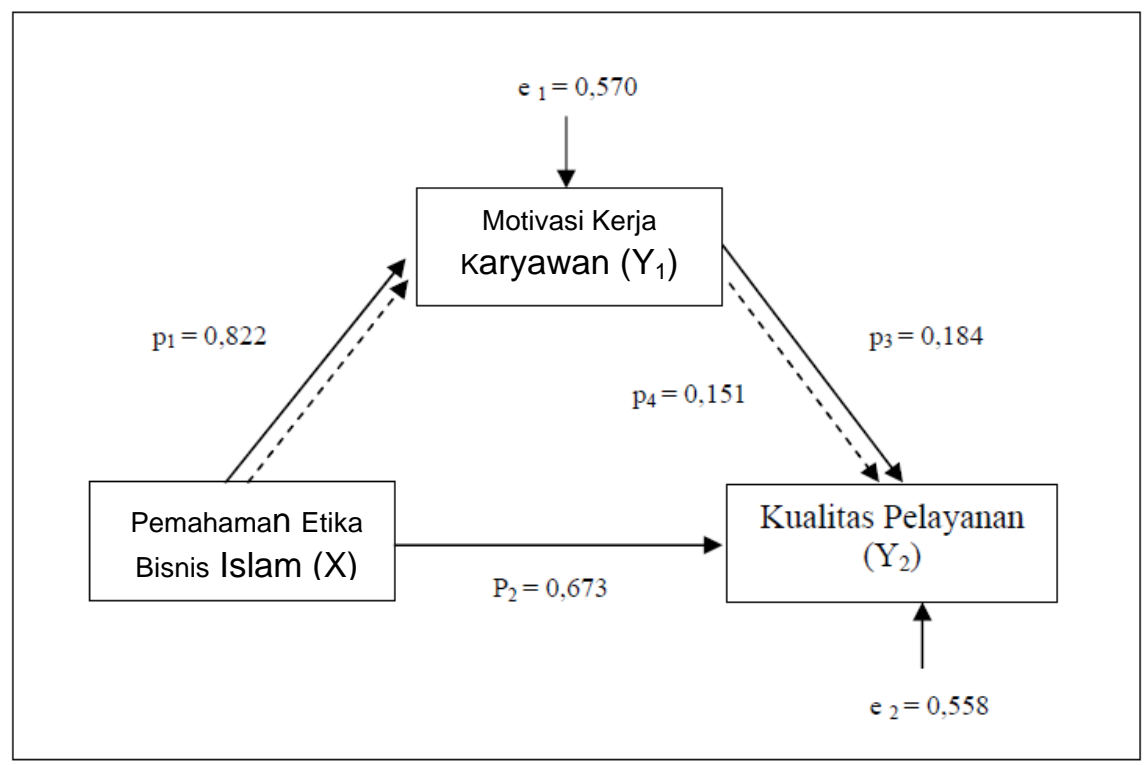

Gambar 2. Validasi Model Gambar Jalur Akhir

5. Langkah kelima

Langkah kelima dalam analisis jalur adalah melakukan interpretasi terhadap hasil penelitian.

a. Pengaruh Pemahaman etika bisnis Islam terhadap motivasi kerja karyawan

Hipotesis

H0 : Tidak ada pengaruh pemahaman etika bisnis Islam terhadap motivasi kerja karyawan

H1 : Terdapat pengaruh pemahaman etika bisnis Islam terhadap motivasi kerja karyawan 
Kriteria uji

Jika sig penelitian $(\mathrm{t})<0,05$ maka $\mathrm{H} 0$ ditolak dan $\mathrm{H} 1$ diterima

Jika sig penelitian $(\mathrm{t})>0,05$ maka $\mathrm{H} 1$ ditolak dan $\mathrm{H} 0$ diterima

Hasil perhitungan menunjukkan taraf signifikansi sebesar 0,000< 0,05 maka $\mathrm{H} 0$ ditolak dan $\mathrm{H} 1$ diterima. Hal ini berarti terdapat pengaruh pemahaman etika bisnis Islam terhadap motivasi kerja karyawan. Besar pengaruh yang diperoleh adalah 0,822. Angka ini menunjukkan bahwa pemahaman etika bisnis Islam memiliki pengaruh signifikan terhadap motivasi kerja karyawan sebesar 82,2 persen, sedangkan sisanya 17,8 persen dipengaruhi oleh faktor diluar model. Berpengaruh signifikan dapat diartikan bahwa apabila semakin tinggi pemahaman etika bisnis Islam karyawan maka karyawan akan semakin memiliki motivasi yang tinggi untuk dalam bekerja pada PT. Bank Muamalat, Tbk. Cabang Jambi.

b. Pengaruh pemahaman etika bisnis Islam terhadap kualitas pelayanan Hipotesis

H0 : Tidak ada pengaruh pemahaman etika bisnis Islam terhadap kualitas pelayanan

H1 : Terdapat pengaruh pemahaman etika bisnis Islam terhadap kualitas pelayanan

Kriteria uji

Jika sig penelitian $(\mathrm{t})<0,05$ maka $\mathrm{H} 0$ ditolak dan $\mathrm{H} 1$ diterima

Jika sig penelitian $(\mathrm{t})>0,05$ maka $\mathrm{H} 1$ ditolak dan $\mathrm{H} 0$ diterima

Hasil perhitungan menunjukkan taraf signifikansi sebesar 0,000< 0,05 maka $\mathrm{H} 0$ ditolak dan $\mathrm{H} 1$ diterima. Hal ini berarti terdapat pengaruh pemahaman etika bisnis Islam terhadap kualitas pelayanan. Besar pengaruh yang diperoleh adalah 0,673. Angka ini menunjukkan bahwa pemahaman etika bisnis Islam memiliki pengaruh signifikan terhadap kualitas pelayanan sebsar 67,3 persen, sedangkan sisanya 32,7 
persen dipengaruhi oleh faktor diluar model. Berpengaruh signifikan dapat diartikan bahwa semakin tinggi pemahaman etika bisnis Islam karyawan maka pelayanan dalam bekerja pada PT. Bank Muamalat Cabang Jambi akan semakin berkualitas.

c. Pengaruh motivasi kerja terhadap kualitas pelayanan Hipotesis

H0 : Tidak ada pengaruh motivasi kerja terhadap kualitas pelayanan

H1 : Terdapat pengaruh motivasi kerja terhadap kualitas pelayanan

Kriteria uji

Jika sig penelitian $(\mathrm{t})<0,05$ maka $\mathrm{H} 0$ ditolak dan H1diterima

Jika sig penelitian $(\mathrm{t})>0,05$ maka $\mathrm{H} 1$ ditolak dan $\mathrm{H} 0$ diterima

Hasil perhitungan menunjukkan taraf signifikansi sebesar 0,039<0,05 maka H0 ditolak dan $\mathrm{H} 1$ diterima. Hal ini berarti terdapat pengaruh motivasi kerja karyawan terhadap kualitas pelayanan pada PT. Bank Muamalat, Tbk. Cabang Jambi. Besar pengaruh yang diperoleh adalah 0,184. Angka ini menunjukkan bahwa motivasi kerja karyawan memiliki pengaruh signifikan terhadap kualitas pelayanan yang diberikan karyawan sebesar 18,4 persen, sedangkan sisanya 81,6 persen dipengaruhi oleh faktor diluar model. Berpengaruh signifikan dapat diartikan bahwa apabila karyawan merasa puas maka kualitas pelayanannya pun akan meningkat.

\section{B. Analisis Hasil Penelitian}

Hasil analisis data secara statistik membuktikan bahwa terdapat pengaruh signifikan secara langsung antara pemahaman etika bisnis Islam terhadap motivasi kerja yang ditunjukkan dengan nilai standardized direct effect sebesar 0,822. Penelitian ini menemukan pengaruh signifikan secara langsung antara pemahaman etika bisnis Islam terhadap motivasi kerja karyawan. 
Hasil analisis data secara statistik membuktikan bahwa terdapat pengaruh signifikan secara langsung pemahaman etika bisnis Islam terhadap kualitas pelayanan karyawan yang ditunjukkan dengan nilai standardized direct effect sebesar 0,673. Penelitian ini menemukan pengaruh signifikan secara langsung antara pemahaman etika bisnis Islam terhadap kualitas pelayanan karyawan.

Hasil analisis data secara statistik membuktikan bahwa terdapat pengaruh signifikan secara langsung antara motivasi kerja karyawan terhadap kualitas pelayanan karyawan yang ditunjukkan dengan nilai standardized direct effect sebesar 0,184. Penelitian ini menemukan pengaruh signifikan secara lagsung antara motivasi kerja karyawan kerja karyawan terhadap kualitas pelayanan keryawan.

\section{KESIMPULAN dan SARAN}

\section{A. Kesimpulan}

Hasil analisis data secara statistik membuktikan bahwa terdapat pengaruh signifikan secara langsung antara pemahaman etika bisnis Islam terhadap motivasi kerja yang ditunjukkan dengan nilai standardized direct effect sebesar 0,322. Penelitian ini menemukan pengaruh signifikan secara langsung antara pemahaman etika bisnis Islam terhadap motivasi kerja karyawan. Hasil analisis data secara statistik membuktikan bahwa terdapat pengaruh signifikan secara langsung pemahaman etika bisnis Islam terhadap kualitas pelayanan karyawan yang ditunjukkan dengan nilai standardized direct effect sebesar 0,471. Penelitian ini menemukan pengaruh signifikan secara langsung antara pemahaman etika bisnis Islam terhadap kualitas pelayanan karyawan. Hasil analisis data secara statistik membuktikan bahwa terdapat pengaruh signifikan secara tidak langsung antara etika bisnis Islam melalui motivasi kerja karyawan terhadap kualitas pelayanan karyawan yang ditunjukkan dengan nilai standardized direct effect sebesar 0,148. Penelitian 
ini menemukan pengaruh signifikan secara lagsung antara motivasi kerja karyawan kerja karyawan terhadap kualitas pelayanan keryawan. Hasil analisis data secara statistik membuktikan bahwa terdapat pengaruh signifikan secara tidak langsung antara motivasi terhadap kualitas pelayanan melalui pemahaman etika bisnis Islam yang ditunjukkan dengan nilai standardized indirect effect sebesar 0,148.

\section{B. Saran}

Motivasi ditingkatkan dengan cara mengefektifkan peran pimpinan dalam memberikan arahan, bimbingan, petunjuk serta evaluasi berkenaan pelaksanaan tugas dan pekerjaan, sehingga dapat diwujudkan kondusivitas di tempat kerja. Pada sisi lainnya, ganjaran (reward and punisment) yang didasarkan pada hasil kerja karyawan maupun pengembangan karier perlu diperhatikan dengan baik oleh manajamen, sehingga nantinya karyawan dapat terpuaskan akan hasil kerjanya dan mengarah pada peningkatan kualitas pelayanan yang dihasilkan. Pemahaman etika bisnis Islam karyawan lebih ditingkatkan dengan memberikan pendidikan dan pembelajaran kepada karyawan mengenai kaidah-kaidah yang harus dipatuhi dalam menjalankan bisnis secara Islami. Peningkatan kualitas pelayanan kelengkapan sarana dan prasana penunjang perlu diperhatikan seperti perlengkapan keamanan (safety work) agar karyawan merasa aman dan nyaman dalam bekerja.

\section{DAFTAR PUSTAKA}

\section{$\underline{\text { Kitab }}$}

Depag RI, Al-Quran dan Terjemah, Semarang: Diponegoro, 2009

\section{$\underline{\text { Buku }}$}

Ahmad El-Ashker and Rodney Wilson, Islamic Economics A. Short History Leiden Belanda: Konin Kliske Brill NV, 2006.

Amri Amir, Junaidi, dan Yulmardi, Metodologi Penelitian Ekonomi dan Penerapannya Bogor: IPB Press, 2009. 
Anwar Prabu Mangkunegara, Manajemen Sumber Daya Manusia Perusahaan Bandung: PT Remaja Rosda Karya, 2007.

Arman Hakim Nasution, Manajemen Industri Yogyakarta: CV. Andi Offset, 2006.

Arman Hakim Nasution, Manajemen Industri Yogyakarta: CV. Andi Offset, 2006.

Burhan Bungin, Metodologi Penelitian Kuantitatif,Jakarta: Kencana Prenada Media Group, 2008.

Departemen Pendidikan dan Kebudayaan, Kamus Besar Bahasa Indonesia Jakarta: Balai Pustaka.

Edy Sutrisno, Manajemen Sumber Daya Manusia Jakarta:Kencana Prenada Media Group, 2009..

Faisal Badroen, Etika Bisnis dalam Islam Jakarta: Kencana Prenada Media Group, 2007.

Fandy Tjiptono, Menejemen Pelayanan Jasa Yogyakarta: Andi, 2006.

Farida Jasfar, Manajemen Jasa Pendekatan Terpadu Jakarta:Ghalia Indonesia, 2005.

Hafas, "Etika dan Manajemen Sumber Daya Manusia", Makalah, PPs IAIN STS Jambi, 2013.

Hendri Tanjung dan Abrista Devi, Metode Penelitian Ekonomi Islam, Bekasi: Gramata Publishing, 2013.

Heru Satyanugraha, Etika Bisnis-Prinsip dan Aplikasi.

HM Nadratuzzaman Hosen, dkk, Dasar-Dasar Ekonomi Islam Jakarta: Pusat Komunikasi Ekonomi Syariah, 2008.

I made Wirartha, Metodologi Penelitian sosial Ekonomi Yogyakarta: CV. ANDI OFFSET, 2006.

Kadarisman, Manajemen Pengembangan Sumber Daya Manusia Jakarta: PT Raja Grafindo Persada, 2013.

Karl Haman, Peter Koslowski, and Christoph Luetge, Globalisation and Business Ethics USA: Ashgate Publising Company, 2007.

Kultar Singh, Quantitative Social Research Methods Singapore: Publications Asia Pasific Ltd, 2007.

Masudul Alam Choudhury, Islamic Economic And Finance USA: Emerald Grup, 2011. 
174 | Muhammad Andriyansyah dan Yudha Gusti Wibowo : Pengaruh Pemahaman Etika Bisnis.....

Moenir, Manajemen Pelayanan Umum diIndonesia, Jakarta: Bumi Aksara. .

Muhamad, Metodologi Penelitian Ekonomi Islam Pendekatan Kuantitatif Jakarta: PT. RajaGrafindo Persada, 2008.

Muhammad Alimin, Etika dan Perlindungan Konsumen dalam Ekonomi Islam Yogyakarta: BPFE.

Muhammad Ayub, Understanding Islamic finance Jakarta, PT Gramedia Pustaka Utama, 2009.

Muhammad Iqbal dan William Hunt, Ensiklopedi Ringkas Tentang Islam Jakarta: Taramedia, 2003.

Muhammad Sharif Chaudhry, Sistem Ekonomi Islam Prinsip Dasar Jakarta: Kencana Prenada Media Group, 2012.

R. Lukman Fauroni, Etika Bisnis dalam Al-Qur'an Yogyakarta: PT. LKIS Pelangi Aksara, 2006.

S. M. Ghazanfar, Medieval Islamic Economic Thought London: Routledgecurzon.

Sambas Ali Muhidin dan Maman Abdurahman, Analisis Korelasi, Regresi, dan Jalur Dalam Penelitian Bandung: CV. Pustaka Setia, 2007.

Sayid Syekh pada mata kuliah Statistik Ekonomi, Pasca Sarjana IAIN STS Jambi tanggal 24 Mei 2013

Sayid Syekh, Pengantar Statistik Ekonomi dan Sosial Jakarta: Gaung Persada Perss, 2011.

Sayid Syekh, Pengantar Statistik Ekonomi dan Sosial Jakarta: Gaung Persada, 2011.

Shaykh Tosun Bayrak, The Path Of Muhammad Word Wisdom, 2006.

Siswanto, Pengantar Manajemen Jakarta: PT Bumi Aksara, 2011.

Sudarwan Danim, Kinerja Staf dan Organisasi Bandung: CV Pustaka Setia, 2008.

Sugiyono, Metode Penelitian Kuantitatif Kualitatif dan R\&D Bandung: Alfabeta, 2010.

Sugiyono, Metode Penelitian Kuantitatif Kualitatif dan R\&D, Bandung: ALFABETA, 2010.

Suharsimi Arikunto, Prosedur Penelitian Suatu Pendekatan Praktik Jakarta: PT. Rineka Cipta, 2006. 
Syafi'I Antonio, Bank Syari'ah dari Teori ke Praktik Jakarta: Tazkia Cendikia, 2003.

Tom Gunadi, Memantapkan Hubungan Dengan Pelanggan Bandung: ANGKASA.

Winardi, Manajemen Prilaku Organisasi. Bandung: PT Citra Aditya Bakti. 2012

Abdul Wahab, "Faktor-faktor yang Mempengaruhi Perilaku Masyarakat Muslim dalam Memilih Perbankan Syariah di Kota Makasar", Tesis Magister, UIN Alauddin Makasar.

Ahmad Diqin, "Pengaruh Pelayanan Costomer Servic Terhadap Kepuasan Nasabah diBank Muamalat”,Proposal Penelitian, 2014.

Betty Sakura, Pengaruh Pemahaman Tentang Etika Bisnis Islam Terhadap Kualitas Pelayanan Nasabah Pada Bank Syariah Mandiri Jambi: Tesis Pasca Sarjana IAIN STS Jambi, 2006.

Hendri, "Pengaruh Kualitas Pelayanan Terhadap Citra dan Kepuasan Nasabah Bank Mega Syariah”, Tesis Magister, PPs IAIN STS Jambi, 2013.

\section{Internet}

Diposkan oleh Hanifa Azlansyah di 10/14/2014 12. 17. 00 AM http://dedylondong. blogspot. com/2011/11/kualitas-pelayanan. html http://duniailmuweb. blogspot. com/2012/05/bab-i-pendahuluan_29. html http://eprints. undip. ac. id/29512/1/Skripsi008. pdf http://eprints. undip. ac. id/29512/1/Skripsi008. pdf

http://fahmyzone. blogspot. com/2012/09/etika-bisnis-dalam-islam-vs-nonislam. html

http://pengertiandefinisi.com/pengertian-karyawan-dan-jenis-jenis-karyawandi-perusahaan/

http://prasetyaferilian. blogspot. com/2011/11/faktor-faktor-yang-mempengaruhi. html

http://Winarti135. blogspot. com/2011/12/etika-bisnis-syariah. html 
176 | Muhammad Andriyansyah dan Yudha Gusti Wibowo : Pengaruh Pemahaman Etika Bisnis.....

http://www. academia. edu/13848619/PENGARUH_RELIGIUSITAS_ DAN_ ETIKA_KERJA_ISLAMI_TERHADAP_MOTIVASI_ KERJA

http://www. kajianpustaka. com/2013/04/kualitas-pelayanan-pelanggan. html

Maive Suuroja, Service Quality - Main Conceptualization and Critique Tartu: Tartu University Press, 2003 hal 13. http://ssrn. com http:/www. motivasi-islami. com/motivasi-kerja-dalam-islam/ https://emayasila. wordpress. com/2012/10/17/teori-pelayanan/ https://kecerdasanmotivasi. wordpress. com/2012/05/29/etika-dan-moralitasdalam-hubungan-kerja/

https:/www. facebook. com/.../PENGERTIAN\%20ETIKA\%20DAN\%20 ETIKE

https:/www. google. co. id/search?q=pertumbuhan+aset+bank+muamalat. Perkembangan Bank Syariah di Indonesia,http://www. bi. go. id. Tribun News. com. 9 Oktober 2013 